$\begin{array}{r}\text { Phinisi Integration Review } \\ \text { Vol. 2, No.1, Februari 2019 Hal 032-038 } \\ \text { Website: http://ojs.unm.ac.id/pir } \\ \text { p-ISSN: 2614-2325 dan e-ISSN: 2614-2317 } \\ \hline\end{array}$

\title{
Keefektifan Strategi Giving, Question, and Getting Answer Terhadap Karakter Siswa Pada Hasil Belajar Membaca Intensif Pada Siswa Kelas IV Madrasah Iptidayah Al Abrar Makassar
}

\author{
Ummu Khaltsum ${ }^{(1)}$, Muh Irwinto Imran ${ }^{(2)}$ \\ Fakultas Keguruan dan Ilmu Pendidikan, Universitas Muhammadiyah Makassar \\ email: ummukhaltsum@unismuh.ac.id
}

\begin{abstract}
Abstrak. Penelitian ini dilatarbelakangi oleh rendahnya hasil belajar membaca pada siswa kelas IV Madrasah Iptidaiyah Al Abrar Makassar. Kegiatan pembelajaran membaca pada siswa kelas Madrasah Iptidaiyah Al Abrar Makassar selama ini siswa kurang aktif dalam memberikan pertanyaan kepada guru selain yang ada dalam buku teks. Nilai-nilai karakter dalam pembelajaran Bahasa Indonesia dapat diwujudkan jika guru memahami bahwa pembelajaran Bahasa Indonesia yang dberikan guru dalam rangka melatih keterampilan berbahasa peserta didik baik secara lisan maupun tertulis yang sesuai dengan fungsinya. Namun kenyataannya, guru sering terjebak dalam pembelajaran bahasa Indonesia yang lebih menekankan tentang teori kebahasaan. Pembelajaran lebih bersifat konvensional dan materi pembelajaran lebih pada penguasaan konsep-konsep bukan kompetensi. Dengan adanya permasalahan tersebut, bisa dipastikan tujuan membaca tidak akan tercapai secara maksimal. Hal tersebut menggugah peneliti untuk melakukan penelitian dengan judul "Keefektifan Strategi Giving Question and Getting Answer terhadap Hasil Belajar MembacaIntensif pada Siswa Kelas IV Madrasah Iptidaiyah Al Abrar Makassar". Penelitian ini menggunakan prosedur penelitian Eksprimen. Subjek penelitian ini adalah siswa Kelas Madrasah Ibtidaiyah Al Abrar Makassar. Teknik pengambilan sampel yang digunakan adalah purposive sampling. Teknik pengumpulan data dilakukan dengan memberikan tes awal (pretest) kepada satu kelompok yang disebut sebagai kelas eksperimen. Kemudian diberikan perlakuan (treatment) dengan menerapkan metode pembelajaran giving question and getting answer, selanjutnya diberikan tes akhir (post-test) pada akhirpembelajaran. Keberlanjutan penelitian ini akan menghasilkan produk dalam bentuk bahanajar dan publikasi ilmiah pada jurnal nasional maupun international.
\end{abstract}

Kata Kunci: Strategi Giving Question and Getting Answer; pretest; treatment; postest; Nilai karakter; hasil belajar. 


\section{PENDAHULUAN}

Pendidikan merupakan suatu aspek kehidupan yang sangat mendasar bagi pembangunan bangsa dan Negara. Dalam penyelenggaraan pendidikan di sekolah yang melibatkan guru sebagai pendidik dan siswa sebagai peserta didik, diwujudkan dengan adanya interaksi belajar mengajar atau proses pembelajaran. Dalam konteks penyelenggaraan ini, guru dengan sadar merencanakan kegiatan pengajarannya secara sistematis dan berpedoman pada seperangkat aturan dan rencana tentang pendidikan yang dikemas dalam bentuk kurikulum.

Cerminan nilai-nilai karakter dalam pembelajaran Bahasa Indonesia dapat diwujudkan jika guru memahami bahwa pembelajaran Bahasa Indonesia yang diberikan guru dalam rangka melatih keterampilan berbahasa peserta didik baik secara lisan maupun tertulis yang sesuai dengan fungsinya. Namun kenyataannya, guru sering terjebak dalam pembelajaran bahasa Indonesia yang lebih menekankan tentang teori kebahasaan. Sebagaimana yang dikemukakan Slamet (2007: 6), bahwa pengajaran bahasa Indonesia adalah pengajaran keterampilan berbahasa bukan pengajaran tentang kebahasaan. Teori-teori bahasa hanya sebagai pendukung atau penjelas dalam konteks, yaitu yang berkaitan dengan keterampilan tertentu yang tengah diajarkan. Untuk itu, proses pembelajaran Bahasa Indonesia sebagimana yang dituangkan dalam Standar Isi mata pelajaran Bahasa Indonesia (Mendiknas, 2006: 232) menekankan sebagai berikut dalam Undang-Undang Republik Indonesia Nomor 20 Tahun 2003 tentang Sistem Pendidikan Nasional, dinyatakan: Pendidikan adalah usaha sadar dan terencana untuk mewujudkan suasana belajar dan proses pembelajaran agar siswa secara aktif mengembangkan potensi dirinya untuk memiliki kekuatan spiritual,keagamaan, pengendalian diri,kepribadian, kecerdasan, akhlak mulia,serta keterampilan yang diperlukan dirinya,masyarakat, bangsa dannegara (UU RI No. 20 Tahun 2003 dalam Wahyudin 2008:1.34).

Dalam pasal 7 Undang-Undang Republik Indonesia Nomor 20 Tahun 2003, ditegaskan bahwa orangtua dari anak usia wajib belajar berkewajiban memberikanpendidikan dasar kepada anaknya. Sedangkan masyarakat berkewajibanmemberikan dukungan sumber daya dalam penyelenggaraan pendidikan. Adapun kewajiban pemerintah dan pemerintah daerah wajib memberikanlayanan dan kemudahan serta menjamin terselenggaranya pendidikan yangbermutu bagi setiap warga tanpa diskriminasi. Selain itu Oyewumi (2010:201)mengatakan bahwa:

Education is said tobe a powerful instrument of change and development in anysociety where it is introduced. Researches have also confirmed that whatever changes and development intended by any society should be taught in school. These assertions are evidently supported by the United Nations Declaration on Human rights (1948) which stipulates that every child has a right to education.

Maksud pernyataan tersebut adalah pendidikan dikatakan menjadi suatualat perubahan dan pengembangan yang kuat dalam masyarakat dimanapendidikan itu diperkenalkan. Pendidikan membentuk kepribadian diri dari setiapmasyarakat. Pendidikan menanamkan pengetahuan dan pertumbuhan masyarakat tergantung pada kualitas pendidikan yang disampaikan.

Sebagaimana diketahui bahwa siswa SD memiliki karakteristik yangsukabermain, aktif bergerak, suka dipuji, serta senang berkompetisi. Oleh karena itu, guru perlu merancang pembelajaran yang sesuai dengan karakteristik siswa SD tersebut. Jika guru tidak mampu merancang pembelajaran yang sesuai dengan karakteristik siswa maka akan menyebabkan siswa kurang termotivasi dan kurang tepat sasaran dalam pembelajaran. Pendidikan Sekolah Dasar dapat diartikan sebagai proses membimbing,mengajar dan melatih siswa yang berusia 6-13 tahun untuk memberi bekal kemampuan dasar.

Pengetahuan Sosial (IPS), Pendidikan Kewarganegaraan (PKn), Bahasa Daerah, Seni Budaya dan Keterampilan (SBK), serta Bahasa Indonesia. Ketujuh mata pelajaran yang ada di Sekolah Dasar tersebut terdapat beberapa keterampilan yang harus dikuasai oleh siswa,yaitu keterampilan membaca, menulis dan berhitung. Keterampilan membaca, menulis dan 
berhitung (calistung) merupakan tujuan pertama dan utama dan sering disebut juga sebagai tujuan yang paling fundamental, karena sifatnya sangat menentukan baik tidaknya keterampilanketerampilan yang lain, seperti keterampilan dalam berinteraksi dalam kehidupan masyarakat maupun bernegara. Keterampilan ini merupakan prasyarat penting bagi setiap orang untuk hidup secara wajar dalam masyarakat. Bisa dibayangkan bagaimana terbatasnya kehidupan orang yang tidak memiliki keterampilan dasar baca, tulis dan hitung ini cenderung akan mengalami berbagaikesulitan karena ketiadaan keterampilan dasar hidup ini (Mikarsa, 2009:1.14).

Salah satu keterampilan berbahasa yang penting yaitu keterampilan membaca (reading skills). Materi yang berkaitan dengan keterampilan membacayang ada di Sekolah Dasar yaitu membaca intensif. Pembelajaran keterampilanmembaca pada materi membaca intensif diharapkan akan melatih siswa dalammemahami suatu teks bacaan. Dalam pembelajaran membaca pada materi membaca intensif selama ini siswa hanya membaca teks dalam buku secara mandiri maupun bersamasama. Selain itu guru memberi tugas untuk menjawab pertanyaan yang ada dalam buku teks tersebut. Siswa kurang aktif dalam bertanya selain yang ada dalam buku teks tersebut. Pembelajaran lebih bersifat konvensional dan lebih banyak berpusat pada guru. Komunikasi lebih banyak satu arah dari guru ke siswa. Metode pembelajaran lebih banyak menggunakan ceramah dan demonstrasi, dan materi pembelajaran lebih pada penguasaan konsep-konsep bukan kompetensi. Dengan pembelajaran Bahasa Indonesia yang berlangsung terus menerus seperti itu maka bisa dipastikan tujuan membaca tidak akan tercapai secara maksimal. Berdasarkan kenyataan itu perluadanya sebuah strategi yang dapat membuat siswa lebih aktif dalam kegiatan pembelajaran.

Agar tercapai tujuan pembelajaran yang sudah ditetapkan oleh guru,perlu adanya startegi pembelajaran yang sesuai dengan materi membaca intensif dan memenuhi prinsip-prinsip umum penggunaan strategi pembelajaran. Salah satustrategi pembelajaran yang cocok dengan karakteristik dan tujuan pembelajaran bahasa
Indonesia khususnya pembelajaran membaca yaitu strategi giving question and getting answer. Menurut Ashari (2012:2), strategi giving question and getting answer merupakan implementasi strategi pembelajaran kontrukstivistik yang menempatkan siswa sebagai subyek dalam pembelajaran. Artinya, siswa mampu merekonstruksi pengetahuannya sendiri sedangkan guru hanya sebagai fasilitator saja. Strategi ini dikembangkan untuk melatih siswa memiliki kemampuan danketerampilan bertanya dan menjawab pertanyaan. Pada dasarnya strategi tersebutmerupakan modifikasi metode tanya jawab dan metode ceramah yang merupakan kolaborasi dengan menggunakan potongan-potongan kertas sebagai medianya.

Berdasarkan uraian tersebut peneliti tertarik untuk mengadakan penelitian dengan menerapkan strategi giving question and getting answer pada pembelajaran bahasa Indonesia materi membaca intensif. Judul dalam penelitian ini yaitu "Keefektifan Strategi Giving Question and Getting Answer terhadap Hasil Belajar Membaca Intensif pada Siswa Kelas IVMadrasah Iptidaiyah Al Abrar Makassar".

Berdasarkan dari uraian latar belakang masalah di atas maka muncul sebuah gagasan yaitu: Apakah penerapan strategi giving question and getting answer efektif digunakan dalam penanaman karakter pada pembelajaran membaca intensif pada siswa kelas $1 \mathrm{~V}$ di Madrasah Ibtidaiyah Al Abrar Makassar?

Tujuan yang ingin dicapai dalam penelitian ini adalah untuk mendeskripsikan keefektifan strategi giving question and getting answer terhadap penanaman karakter pada hasil belajar membaca intensif pada siswa kelas IV di Madrasah Iptidaiyah Al Abrar Makassar.

\section{METODE PENELITIAN}

\subsection{Jenis penelitian}

Metode penelitian merupakan usaha untuk menemukan, mengembangkan, dan menguji suatu kebenaran pengetahuan dengan menggunakan cara-cara ilmiah. Hal-hal yang harus diperhatikan dalam penelitian adalah metode yang digunakan harus disesuaikan dengan objek penelitian dan tujuan yang akan 
dicapai sehingga penelitian akan berjalan dengan sistematis.

Untuk memperoleh data yang akurat sesuai dengan masalah penelitian ini dirancang secara deskriptif quantitative. Desain penelitian yang digunakan dalam penelitian ini adalah desain penelitian yang bersifat pre-eksperimental. Desain adalah rancangan sebagai pedoman atau jalur dalam melakukan penelitian.

Kegiatan penelitian ini bertujuan untuk mengetahui keefektifan metode giving question and getting answer terhadap hasil belajar membaca intensif siswa di MadrasahIptidaiyah Al Abrar Makassar dan pengujian hipotesis dilakukan untuk mengetahui efektif tidaknya metode giving question and getting answer dalam membaca intensif siswa.

Jenis penelitian yang akan digunakan dalam penelitian ini adalah dengan menggunakan metode pre experimental one group design. Metode ini diberikan pada satu kelompok saja tanpa kelompok pembanding.

\section{$\mathrm{O} 1 \mathrm{X} \mathrm{O} 2$}

Gambar 3.1. Rumus PreExperiment One Group Pretest-Posttest Design

\subsection{Lokasi, Waktu dan Subjek Penelitian}

Penelitian ini akan dilaksanakan di Madrasah Iptidaiyah Al Abrar Makassar. Pelaksanaan penelitian di rencanakan pada semester ganjil tahun ajaran 2017/2018. Subjek atau sasaran penelitian ini adalah siswa kelas IV Madrasah Iptidaiyah Al Abrar Makassar, dengan jumlah siswa 24 orang yang terdaftar aktif pada semester genap tahun ajaran 2016/2017, terdiri atas 11 orang laki-laki dan 13 orang perempuan, dengan sasaran utama meningkatkan hasil belajar membaca intensif dengan menggunakan metode giving question and getting answer.

Adapun tabel jumlah siswa sebagai berikut:

\begin{tabular}{|l|l|l|l|l|}
\hline No & Kelas & $\begin{array}{l}\text { Laki- } \\
\text { laki }\end{array}$ & Perempuan & Jumlah \\
\hline 1 & IV & 11 & 13 & 24 \\
\hline
\end{tabular}

Tabel 3.1 Jumlah Siswa Kelas IV Madrasah Iptidaiyah Al Abrar Makassar

\subsection{Variabel Penelitian dan Definisi Operasional}

\subsubsection{Variabel Penelitian}

Variabel penelitian merupakan gejala yang menjadi fokus peneliti untuk diamati (Sugiyono, 2002: 2). Dalam penelitian ini berdasarkan judul yang telah diambil "keefektifan strategi giving question and getting answer terhadap hasil belajar membaca intensif pada siswa kelas $1 \mathrm{~V}$ di Madrasah Iptidaiyah Al Abrar Makassar", maka variabel yang digunakan adalah dependent variable strategi giving question and getting answer dan independentvariable belajar membaca intensif.

\subsubsection{Definisi Operasional Variabel}

Strategi giving question and getting answer adalah strategi yang dikembangkan untuk melatih siswa agar supaya memiliki kemampuan, keterampilan bertanya dan menjawab pertanyaan karena pada dasarnya strategi ini merupakan modifikasi dari strategi tanya jawab yang berkolaborasi dengan menggunakan potongan-potongan kertas sebagai medianya.

Membaca intensifadalah kegiatan membaca yang dilakukan secara cermat dan teliti terhadap testyag dibaca untuk mencari informasi atau menetukan sebuah pokok persoalan/perihal yang menarik untuk dapat/layak dijadikan sebagai bahan diskusi

\subsection{Fokus Penelitian}

Uraian-uraian di atas, telah dikemukakan bahwa keadaan awal siswa kelas IV yang ingin ditingkatkan melalui kegiatan penelitian dengan menerapkan strategi giving question and getting answer. Pada pelaksanaannya, penelitian memfokuskan pada aspek yaitu:

3.4.1 Penggunaan strategi giving question and getting answer yaitu peneliti mengamati dan menilai aktivitas siswa selama mengikuti proses belajar mengajar.

\subsubsection{Peningkatan keefektifan} membacaintensif siswa, yaitu dengan melakukan 
penilaian terhadap tes hasil belajar bahasa Indonesia pada penelitian.

\subsection{Instrument Penelitian}

Instrument penelitian dalam penelitian in ada dua yaitu pretestandposttest. Hal pertama dalam pelaksanaan eksperimen menggunakan desain subyek tunggal ini dilakukan dengan memberikan tes kepada subjek disebut pre-test (O1) untuk mengetahui kemampuan awal siswa dalam membaca intensif. Setelah didapat data siswa yang memiliki masalah dalam membaca intensif, maka dilakukan treatmentdengan menggunakan metode givingquestionandgettingansweruntuk jangka waktu tertentu.

Bandingkan O1 dan O2 untuk menentukan seberapa besar perbedaan yang timbul, jika sekiranya ada sebagai akibat diberikannya treatment. Kemudian data tersebut dianalisis dengan menggunakan t-test (Arikunto; 2002) Untuk lebih jelasnya dapat digambarkan sebagai berikut:

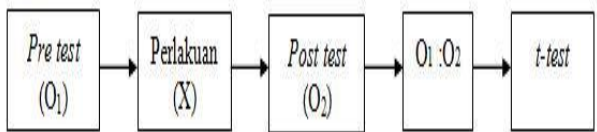

Gambar 3.2 Langkah-Langkah Penelitian

Keterangan :

1) O1 merupakan pretest

2) X merupakan treatment

3) $\mathrm{O} 2$ merupakan posttest

4) Bandingkan $\mathrm{O} 1$ dan $\mathrm{O} 2$

5) Proses analisis data, menggunakan rumus $t$-test.

\subsection{Teknik Pengumpulan Data}

Penelitian ini adalah penelitian deskriptif kuantitatif, dimana proses penelitian menggunakan pre-test dan post-test. Adapun prosedur penelitian yang akan dilakukan dalam penelitian ini adalah:

\section{Pre-test}

Peneliti memberikan pre-test kepada siswa sebelum memberikan sebuah tindakan. Pre-test diberikan kepada siswa agar peneliti mengetahui kemampuan membaca intensif siswa.

\section{Treatment}

Setelah diberipre-test peneliti memberikan perlakuan (treatment)kepada siswa dengan menerapkan metode pembelajaran giving question and getting answer. Treatment penanaman karakter ini dilakukan dalam 2 kali pertemuan dan masingmasing menggunakan waktu 2 kali 35 menit setiap tatap muka.

\section{Post-test}

Setelah diberi perlakuan (treatment) peneliti memberikan post-test kepada siswa sebagai test terakhir pada penilitian ini. Pada test terakhir ini bertujuan untuk mengetahui pencapaian penanaman karakter pada kemampuan membaca intensif siswa di Madrasah Iptidaiyah Al Abrar Makassar.

\subsection{Teknik Analisis Data}

Analisis data merupakan salah satu langkah yang sangat penting dalam kegiatan penelitian. Dengan analisis data maka akan dapat membuktikan hipotesis dan menarik kesimpulan tentang masalah yang akan diteliti Rumus tersebut digunakan untuk menghitung keefektivitasan perlakuan yang diberikan kepada subyek penelitian. Rumus ini digunakan untuk desain penelitian subyek tunggal yaitu yang observasinya dilakukan pada saat subyek belum mendapat perlakuan dan setelah subyek mendapat perlakuan. Hasil data inilah yang kemudian dianalisis menggunakan rumus thitung kemudian hasil yang diperoleh dapat menunjukkan apakah perlakuan yang diberikan efektif atau tidak.

\section{HASIL DAN PEMBAHASAN}

\subsection{Hasil Penelitian}

Penelitian ini telah berlangsung selama dua bulan di Madrasah Iptidaiyah Al Abrar Makassar padapenerapan strategi giving question and getting answer efektif digunakan dalam penanaman karakter pada pembelajaran membaca intensif pada siswa kelas $1 \mathrm{~V}$. dalam pelaksanaan penelitan, pengambilan datadan observasi dilakukan oleh dosen peneliti dengan melibatkan mahasiswa sebanyak 3orang. 
Ummu Khaltsum, Muh Irwinto Imran. Keefektifan Strategi Giving, Question, and Getting Answer Terhadap Karakter Siswa Pada Hasil Belajar Membaca Intensif Pada Siswa Kelas IV

Madrasah Iptidayah Al Abrar Makassar

Adapun data yang telah diperoleh berupa data keterampilan siswa dan penerapanmelalui permainan dadu. Sedangkan data keterampilan siswa belum dilakukan karenaproses pembelajaran belum selesai.

Hasil penelitian yang yang telah diperoleh adalah deskriptif kuantitatif dan data observasi pengamatan yang dilakukan oleh mahasiswa. Data tersebut diperoleh setelah memberikan soal tes kepada peserta didik yang selanjutnya akan dianalisis untuk melihat penguasaan kosa kata siswa melalui permainan dadu. Data ini diambil dari satu kelas. Penulis juga mengumpulakn data observasi sebagai bahan rujukan dalam penulisan laporan akhir kedepannya.

\section{SIMPULAN DAN SARAN}

Target yang akan direalisasikan dalam penelitian ini adalah perampungan penelitian dan pembuatan laporan akhir serta excecutive summar. Jurnal adalah luaran dari pelaksanaan penelitian ini untuk sementara. Selanjutnya akan diikutkan pada kegiatan seminar nasional yang relevan dengan bidang keilmuan yang telah diteliti.

\section{DAFTAR RUJUKAN}

Abimanyu, Soli. 2008. Strategi Pembelajaran. Jakarta : Ditjen Dikti Depdiknas.

Akhadiah,Sabarti. 1991.Bahasa Indonesia I, Jakarta: Depdikbud.

Arikunto, Suharsimi. 2002. Prosedur Penelitian: Suatu Pendekatan Praktek. Jakarta: Rineka Cipta.

Arikunto, Suharsimi. 2013. Prosedur Penelitian: Suatu Pendekatan Praktek. Jakarta: PT. Rineka Cipta.

Ashari, Fatkhan. 2012. Model Pembelajaran Giving Question And Getting Answer.
Hamalik, Oemar. 2004. Proses Belajar Mengajar (Cet. 3). Jakarta: PT Bumi Aksara.

Hamdani. 2011. Strategi Belajar Mengajar (Cet. 10). Bandung: CV Pustaka Setia.

Hidayat. 2009. Strategi Pembelajaran Aktif. Yogyakarta: Pustaka Insan Madani.

Mikarsa, Hera Lestari, dkk. 2009. Pendidikan Anak di SD (Cet. 12). Jakarta: Universitas Terbuka.

Mulyati, Yeti, dkk. 2009. Keterampilan Berbahasa SD

Oyewumi, $\quad$ Kassim. 2010. Educationandleadership: $\quad A$ philosophicalperspective.Educationa lResearchandReviews Vol. 5 (5), pp. 201-204.

Online. Availableathttp://www.academicjour nals.org/ERR2

[accessed 01/06/2016].

Rahim, Farida. 2008. Pengajaran Membaca di Sekolah Dasar(Edisi 2 Cet. 2). Jakarta: Bumi Aksara.

Rasyid, Abdul 2012. Pengertian Membaca dan Jenis-jenisnyadiposting dari situs

http://ilmus3mesta.blogspot.com/201 2/02/pengertian-membaca-danjenisjenisnya.html. Diakses tanggal 01/06/2016.

Rusman. 2012. Seri Manajemen Sekolah Bermutu MODEL-MODEL PEMBELAJARANMengembangkan Profesionalisme Guru (Ed. 2). Jakarta: PT Rajagrafindo Persada.

Sanjaya, Wina. 2006. Strategi Pembelajaran Berorientasi Standar Proses Pendidikan. Jakarta: Prenada Media. 
Ummu Khaltsum, Muh Irwinto Imran. Keefektifan Strategi Giving, Question, and Getting Answer Terhadap Karakter Siswa Pada Hasil Belajar Membaca Intensif Pada Siswa Kelas IV

Madrasah Iptidayah Al Abrar Makassar

Santosa, Puji, dkk . 2010. Materi dan Pembelajaran Bahasa Indonesia SD(Cet. 14). Jakarta: Universitas Terbuka

Solchan T, dkk. 2011. Pendidikan Bahasa Indonesia di SD(Cet. 9). Jakarta: Universitas Terbuka.

Sugiyono. 2002. Statistika Untuk Penelitian. Bandung: Alfabeta.

Sugiyono. 2010. Metode penelitian Kuantitatif Kualitatif dan $R \& D$, Bandung : Alfabeta

Sugiyono. 2011. Metode Penelitian Kombinasi (MixedMethods). Bandung: C.V Alfabeta.

Suprijono, Agus. 2012. Cooperative Learning: Teori dan Aplikasi PAIKEM(Cet. 8). Yogyakarta: Pustaka Pelajar.

Tarigan, Henry Guntur. 2008. MEMBACA Sebagai Suatu Keterampilan Berbahasa (Edisi Revisi). Bandung: Angkasa.

Wahyudin, Dinn, dkk. 2008. Pengantar Pendidikan(Cet. 5). Jakarta: Universitas Terbuka.

Wibowo, Wahyu. 2001. Manajemen Bahasa. Jakarta: Gramedia.

Solchan T, dkk. 2011. Pendidikan Bahasa Indonesia di SD(Cet. 9). Jakarta: Universitas Terbuka.

Zaini, Hisyam. 2008. Strategi Pembelajaran Aktif. Yogyakarta: Pustaka Insan Madani. 